\title{
COMPOSIÇÃO QUÍMICA DOS COMPONENTES VOLÁTEIS DE Capsicodendron dinisii SCHWANCKE (CANELLACEAE)
}

\author{
Edson Torres e Alberto Wisniewski Jr* \\ Laboratório de Cromatografia, Universidade Regional de Blumenau, Rua São Paulo, 3250, 89030-080 Blumenau - SC, Brasil \\ Edésio L. Simionatto \\ Departamento de Química, Universidade Regional de Blumenau, Rua Antônio da Veiga, 140, 89012-900 Blumenau - SC, Brasil
}

Recebido em 8/3/09; aceito em 15/6/09; publicado na web em 25/11/09

\begin{abstract}
CHEMICAL COMPOSITION OF VOLATILE COMPONENTS OF Capsicodendron dinisii Schwancke (Canellaceae). The volatile components of the stem bark of Capsicodendron dinisii were obtained by hydrodistillation using a modified Clevenger-type apparatus. The chemical compounds were identified using the arithmetic index and confirmed by GC-MS. Twenty-three compounds suggest the identified representing almost $90 \%$ of the total oil composition. Limonene $(68.5 \%)$ was the major compound found. The stereochemistry of limonene was determined and was found to be represented by (+)-limonene (94\%) and (-)-limonene (6\%). The presence of drimenol $(0.7 \%)$, a drimane sesquiterpenoid, confirmed the volatile components characteristics of the Canellaceae family.
\end{abstract}

Keywords: Capsicodendron dinisii; volatile components; limonene.

\section{INTRODUÇÃO}

A espécie em estudo, Capsicodendron dinisii Schwancke (Canellaceae), conhecida popularmente no Brasil como "pimenteira", pertence à família Canellaceae, sendo que o gênero Capsicodendron ocorre apenas no Brasil e compreende só três espécies. ${ }^{1,2}$

Sua distribuição geográfica segue desde os estados de Minas Gerais até o Rio Grande do Sul no Planalto Meridional e Serra da Mantiqueira. É uma árvore pioneira, característica e exclusiva dos capões da região de campos e da Floresta Ombrófila Mista do Planalto Meridional do sul do Brasil. ${ }^{3}$

A casca, de sabor picante como a pimenta verdadeira, possui propriedades medicinais e é levemente entorpecente. ${ }^{3} \mathrm{O}$ nome popular "pau-para-tudo", usado em Santa Catarina, sugere amplas utilidades medicinais sendo considerado remédio para todos os males (panacéia). ${ }^{2}$

Testes realizados para pesquisa de óleos essenciais evidenciaram que a $C$. dinisii possui acentuado odor aromático produzido pelos componentes voláteis encontrados no caule e folhas. ${ }^{4} \mathrm{O}$ aroma é suave e agradável, sendo uma importante opção para a indústria de cosméticos e perfumaria. ${ }^{5}$

No primeiro estudo com a $C$. dinisii foram realizadas extrações do óleo essencial utilizando o aparelho tipo Clevenger modificado funcionando por $5 \mathrm{~h}$. Foi extraído óleo essencial das folhas com rendimento médio de $0,7 \%$ e dos ramos com rendimento médio de 0,2\%, obtendo-se um óleo de odor típico e coloração amarelada. $\mathrm{O}$ óleo essencial extraído das folhas de $C$. dinisii foi submetido à cromatografia em camada delgada, sugerindo a identificação do componente cineol. ${ }^{4}$

Através de estudos realizados sabe-se que os compostos capsicodendrina e o cinamodial, presentes no extrato clorofórmico de amostras da casca da raiz de $C$. dinisii, apresentaram atividade citotóxica contra o carcinoma Eagle's $9 \mathrm{~KB}$ e frente à cultura celular de nasopharynx. Neste mesmo estudo foram isolados o $6 \beta$-acetoxi-isodrimenina, ugandensolídeo e o futronolídeo. ${ }^{6}$ O composto citotóxico cinamosmolídeo foi isolado do extrato clorofórmico de amostras do ramo e folha de $C$. dinisii. ${ }^{6}$ A cap-

*e-mail: albertow@furb.br sicodendrina foi evidenciada como sendo o primeiro tetrâmero sesquiterpênico a ser descoberto, sendo isolado de $C$. dinisii. ${ }^{6,7}$ Desta planta foram isolados pela primeira vez, através do extrato hexânico de amostras da casca do tronco, os compostos poligodial, isopoligodial, mukaadial e poligonona, pertencentes ao grupo dos sesquiterpenos drimânicos, sendo característicos da família Canellaceae. ${ }^{8}$ Verificou-se que o sesquiterpeno drimânico cinamodial, isolado do extrato hexânico da casca do tronco de $C$. dinisii, apresentou atividade moluscicida. ${ }^{9}$

Os sesquiterpenos drimânicos são uma classe de hidrocarbonetos saturados derivados do álcool sesquiterpênico drimenol. ${ }^{10}$ Estes apresentam diversas atividades biológicas, como desestimulantes da alimentação de insetos, anticancerígenas, antibióticas e moluscicidas. ${ }^{9}$ Estudos ampliados sobre as atividades biológicas dos sesquiterpenos drimânicos atribuíram mais algumas funções a estes compostos, como, bactericida, antifúngica, controlador do crescimento de plantas, citotóxica, fitotóxica e efeito piscicida. ${ }^{10}$

Portanto, a proposta deste estudo tem como objetivo a extração e a caracterização dos componentes voláteis de $C$. dinisii por apresentarse como um estudo inédito. Assim, também podemos salientar a importância da pesquisa relacionada à extração e identificação de componentes voláteis, associadas à importância econômica das plantas aromáticas e à aplicação de seus componentes como fonte de substâncias ao desenvolvimento de fármacos e outros agentes bioativos. ${ }^{11}$

\section{PARTE EXPERIMENTAL}

\section{Coleta e preparo da amostra}

Coletaram-se aproximadamente $230 \mathrm{~g}$ da casca de Capsicodendron dinisii em novembro de 2006, na cidade de Guarapuava, estado do Paraná, próximo ao Rio Jordão. A espécie está localizada em um fragmento de Floresta Ombrófila Mista (Mata Atlântica), na altitude de $934 \mathrm{~m}$, com tipo de solo latossolo, nas coordenadas Sul $25^{\circ}$ 26.361 e Norte $51^{\circ}$ 27.346. Uma exsicata está tombada no Herbário da FURB sob o número 6.050. Utilizando um estilete, cortou-se a casca em tiras finas, armazenando-se em caixa térmica com gelo e, posteriormente, em refrigerador até a análise. 


\section{Extração dos componentes voláteis}

Os componentes voláteis foram obtidos, submetendo-se o material vegetal fresco (100 g) à hidrodestilação por $2 \mathrm{~h}$, utilizando um aparelho tipo Clevenger modificado. Os componentes voláteis foram extraídos do hidrolato através da técnica de extração líquido-líquido em 3 etapas com $20 \mathrm{~mL}$ de diclorometano (DCM). A fase orgânica (DCM) foi seca, percolando gota a gota, em um sistema de filtração simples contendo $1 \mathrm{~g}$ de sulfato de sódio anidro $\left(\mathrm{Na}_{2} \mathrm{SO}_{4}\right)$ no papel filtro. $\mathrm{O}$ solvente foi removido em evaporador rotatório à pressão reduzida e os componentes voláteis armazenados em congelador até análise. A extração foi realizada em duplicata. O rendimento médio dos componentes voláteis foi determinado pela relação da massa do óleo obtida e a massa do material vegetal fresco utilizado na extração.

\section{Caracterização dos componentes voláteis}

Os componentes voláteis foram submetidos à análise em cromatógrafo de fase gasosa Varian ${ }^{\circledR} \mathrm{CP}-3800$, acoplado a um espectrômetro de massas Saturn 2000 equipado com coluna capilar CP-Sil 8 CB Low Bleed ( $30 \mathrm{~m}$ x 0,25 mm x 0,25 $\mu \mathrm{m})$.

A programação do forno foi de $50{ }^{\circ} \mathrm{C}$ por $1 \mathrm{~min}, 3{ }^{\circ} \mathrm{C} \mathrm{min}^{-1}$ até $240^{\circ} \mathrm{C}$, permanecendo a esta temperatura por $0,7 \mathrm{~min}$. Empregou-se como gás de arraste o hélio com vazão constante de $1,2 \mathrm{~mL} \mathrm{~min}^{-1}$. A temperatura do injetor foi de $250{ }^{\circ} \mathrm{C}$. A quantificação relativa dos componentes foi determinada por CG-DIC (detector de ionização de chama) sob as mesmas condições analíticas com o detector a $280{ }^{\circ} \mathrm{C}$.

A identificação foi realizada através do índice aritmético (IA) calculado em relação aos tempos de retenção de uma série homologa de n-alcanos $\left(\mathrm{C}_{10} \text { até } \mathrm{C}_{25}\right)^{12} \mathrm{e}$ no padrão de fragmentação observado nos espectros de massas comparados com a espectroteca NIST 02. O Índice Aritmético caracteriza-se pela obtenção dos dados através de um sistema variável de temperatura. Este sistema matemático deriva do Índice de Kovats (IK), no qual os dados são obtidos sob a condição de uma isoterma. ${ }^{12}$ Padrões isolados de heptanal, limoneno, guaicol, cânfora, trans-anetol, safrol, timol, eugenol e terc-butil hidróxitolueno foram empregados como referência para validar o sistema.

A estereoquímica do limoneno, componente majoritário, foi determinada em cromatógrafo de fase gasosa Schimadzu GC-14B, equipado com coluna Beta Dextm 120 (30 m x 0,25 mm x 0,25 $\mu \mathrm{m}$ ) e detector de ionização de chama. A programação do forno foi de $100^{\circ} \mathrm{C}$ por 10 min, $10^{\circ} \mathrm{C} \min ^{-1}$ até $200{ }^{\circ} \mathrm{C}$, permanecendo 10 min nesta temperatura. Empregou-se como gás de arraste nitrogênio com pressão constante de $100 \mathrm{kPa}$. Temperatura do injetor em $250{ }^{\circ} \mathrm{C}$ e detector a $280{ }^{\circ} \mathrm{C}$. Gerenciou-se a quantificação através do software Peak Win 3d. Para a identificação foram empregados os padrões isolados de (+)-limoneno e (-)-limoneno, obtidos comercialmente da Aldrich.

\section{RESULTADOS E DISCUSSÃO}

O processo de hidrodestilação, utilizando aparelho tipo Clevenger modificado, forneceu os componentes voláteis com rendimento médio de $0,17 \pm 0,08 \%$.

O emprego de substâncias padrão como referência auxiliou na confirmação da identificação do limoneno (IA: 1030) e cânfora (IA: 1151). As demais substâncias de referência, heptanal (IA: 900), guaicol (IA: 1089), trans-anetol (IA: 1290), safrol (IA: 1290), timol (IA: 1294), eugenol (IA: 1356) e terc-butil hidróxitolueno (IA: 1504), auxiliaram na elucidação das possíveis variações experimentais dos IA dos componentes voláteis de $C$. dinisii, utilizados para a proposta de identificação através dos respectivos espectros de massas.

A Tabela 1 apresenta a proposta de identificação e a quantificação relativa para os componentes voláteis da $C$. dinisii. Foram relacio- nados 23 compostos pertencentes aos componentes voláteis de $C$. dinisii, totalizando cerca de $90 \%$ da fração analisada, através do IA e pela similaridade dos espectros de massas.

Tabela 1. Composição química dos componentes voláteis de Capsicodendron dinisii Schwancke

\begin{tabular}{|c|c|c|c|}
\hline Compostos & $\begin{array}{c}\text { IA } \\
\text { Teórico }\end{array}$ & $\begin{array}{c}\text { IA } \\
\text { Calculado } \\
\end{array}$ & $\begin{array}{c}\% \text { Relativo } \\
\text { CG-DIC }\end{array}$ \\
\hline 1. (-)- $\alpha$-pineno & 932 & 931 & 1,5 \\
\hline 2. canfeno & 946 & 948 & 0,3 \\
\hline 3. $\beta$-pineno & 974 & 978 & 0,4 \\
\hline 4. mirceno & 988 & 989 & 0,2 \\
\hline 5. p-menta-1(7),8-dieno & 1003 & 1005 & 0,2 \\
\hline 6. $\alpha$-terpineno & 1014 & 1018 & 0,2 \\
\hline 7. o-cimeno & 1022 & 1027 & 1,0 \\
\hline 8. limoneno & 1024 & 1036 & 68,5 \\
\hline 9. $\gamma$-terpineno & 1054 & 1059 & 0,6 \\
\hline 10. terpinoleno & 1086 & 1087 & 0,2 \\
\hline 11. linalol & 1095 & 1101 & 0,6 \\
\hline 12. cânfora & 1141 & 1150 & 0,3 \\
\hline 13. borneol & 1165 & 1177 & 2,3 \\
\hline 14. $\alpha$-terpineol & 1186 & 1186 & 9,9 \\
\hline 15. cis-carveol & 1226 & 1223 & 0,3 \\
\hline 16. nerol & 1227 & 1227 & 0,6 \\
\hline 17. carvona & 1239 & 1248 & 0,2 \\
\hline 18. acetato de bornila & 1287 & 1286 & 0,2 \\
\hline 19. álcool perílico & 1294 & 1303 & 0,3 \\
\hline 20. metil isoeugenol & 1491 & 1498 & 0,2 \\
\hline 21. nerolidol & 1561 & 1562 & 0,9 \\
\hline 22. espatulenol & 1577 & 1581 & 0,7 \\
\hline 23. drimenol & 1766 & 1775 & 0,7 \\
\hline Identificação total & & & 90,3 \\
\hline Monoterpenos & & & 86,8 \\
\hline $\begin{array}{l}\text { Monoterpenos oxigena- } \\
\text { dos }\end{array}$ & & & 14,7 \\
\hline $\begin{array}{l}\text { Sesquiterpenos oxige- } \\
\text { nados }\end{array}$ & & & 2,3 \\
\hline
\end{tabular}

O componente majoritário identificado foi o limoneno, representando $68,5 \%$ da constituição dos componentes voláteis. Os componentes voláteis estão distribuídos em compostos alifáticos, aromáticos, fenilpropanoides, monoterpenos e sesquiterpenos. Foi identificado um alto teor de monoterpenos, com $86,8 \%$, sendo destes $14,7 \%$ de monoterpenos oxigenados. Os monoterpenos cíclicos representam a classe química predominante, encontrando-se ainda constituintes das classes dos álcoois, ésteres, cetonas e éteres. Os principais componentes monoterpênicos foram limoneno, $\alpha$-terpineol, borneol e (-)- $\alpha$-pineno.

O drimenol, sesquiterpeno drimânico, foi identificado com $0,7 \%$. Este composto é importante na caracterização dos componentes voláteis da espécie em estudo, pois os sesquiterpenos drimânicos são característicos da família Canellaceae, ${ }^{8,10}$ estando presentes nos 
cinco gêneros desta família (Capsicodendron, Canella, Cinnamosma, Warburgia e Pleodendron). ${ }^{7,13}$

O (-)-limoneno representa $6 \%$ e o (+)-limoneno representa $94 \%$ do total de limoneno presente nos componentes voláteis de $C$. dinisii. $\mathrm{O}(+)$-limoneno é o composto majoritário encontrado na laranja, assim os componentes voláteis da $C$. dinisii possuem predominância do aroma dos frutos da laranjeira, indicando uma nota floral e cítrica.

\section{CONCLUSÃO}

Através da técnica de hidrodestilação usando o aparelho tipo Clevenger modificado, foram extraídos os componentes voláteis da casca de $C$. dinisii, obtendo-se um rendimento médio de $0,17 \pm$ $0,08 \%$. Utilizando-se as técnicas de caracterização por cromatografia gasosa, espectrometria de massas e índice aritmético, foi proposta a identificação de 23 compostos totalizando cerca de $90 \%$ dos componentes voláteis.

Os componentes voláteis da casca de Capsicodendron dinisii contêm compostos alifáticos, aromáticos, fenilpropanoides, monoterpenos, sesquiterpenos e um sesquiterpeno drimânico. Estes componentes voláteis são caracterizados por um alto teor de monoterpenos (86,8\%), tendo como componente majoritário o limoneno, representando $68,5 \%$ do total, constituído pelas formas quirais (+)-limoneno (94\%) e (-)-limoneno (6\%). O drimenol, sesquiterpeno drimânico, apresentou $0,7 \%$ do total da fração analisada.

\section{AGRADECIMENTOS}

À ANP, FINEP e à Ms. F. S. Torres pela identificação da espécie.

\section{REFERÊNCIAS}

1. Souza, V. C.; Lorenzi, H.; Botânica sistemática: guia ilustrado para identificação das famílias de angiospermas da flora brasileira, baseado em APG I, Nova Odessa: São Paulo, 2005.

2. Reitz, R.; Flora Ilustrada Catarinense: Canellaceae, Herbário Barbosa Rodrigues: Itajaí, 1988.

3. Lorenzi, H.; Árvores brasileiras: manual de identificação e cultivo de plantas arbóreas do Brasil, vol. 2, 4ª ed., Nova Odessa: São Paulo, 2002.

4. Mancini, B.; Tribuna Farmacêutica. 1966, 34, 117.

5. Lorenzi, H.; Árvores brasileiras: manual de identificação e cultivo de plantas arbóreas nativas do Brasil, vol. 1, $1^{\text {a }}$ ed., Nova Odessa: São Paulo, 1992.

6. Mahmoud, I. I.; Kinghorn, A. D.; Cordell, G. A.; Farnsworth, N. R.; J. Nat. Prod. 1980, 43, 365

7. Harinantenaina, L.; Takaoka, S.; J. Nat. Prod. 2006, 69, 1193.

8. Bastos, J. K.; Kaplan, M. A. C.; Gottlieb, O. R.; J. Braz. Chem. Soc. 1999, 10, 136.

9. Bastos, J. K.; Gottlieb, O. R.; Kaplan, M. A. C.; Filho, D. S.; Sarti, S. J.; Rodrigues, C. P. S.; Rev. Ciênc. Farm. 1991, 13, 83.

10. Jansen, B. J. M.; Groot, A.; Nat. Prod. Rep. 2004, 21, 449.

11. Yunes, R. A.; Cechinel Filho, V., orgs.; Química de produtos naturais, novos fármacos e a moderna farmacognosia, $1^{\mathrm{a}}$ ed., Universidade do Vale do Itajaí: Itajaí, 2007.

12. Adams, R. P.; Identification of essential oil components by gas chromatography/mass spectroscopy, Allured Publ. Corp.: Carol Stream, 2007.

13. Amiguet, V. T.; Petit, P.; Ta, C. A.; Nuñez, R.; Sánchez-Vindas, P.; Alvarez, L. P.; Smith, M. L.; Arnason, J. T.; Durst, T.; J. Nat. Prod. 2006, 69, 1005 . 